\title{
Thermal and mechanical joints to cryo-cooled silicon monochromator crystals
}

\author{
A.MacDowell, S.Fakra, G.Morrison, Advanced Light Source, Lawrence Berkeley \\ National Lab., Berkeley Ca 94720, USA
}

\begin{abstract}
We describe the performance of various materials used as the thermal interface between silicon to silicon and silicon to copper joints when operated at $\sim 120 \mathrm{~K}$ and loaded with $\sim 20$ watts of thermal power. We find that only the indium based silicon-to-silicon joint is reliable.
\end{abstract}

\section{INTRODUCTION}

For third generation synchrotron sources, the subtended angular size of the source at the monochromator is usually less than the rocking curve of the monochromator crystal. Increasing the thermal load on monochromator crystals due to white radiation initially produces thermal deformation that results in strained diffraction planes that will degrade the brightness of the source. This is the case for thermal deformations less than the rocking curve of the crystal. Increasing the thermal load further increases the diffraction plane distortion beyond the rocking curve of the crystals, there is then a reduction in the monochromatic x-ray throughput. A common way to deal with this thermal distortion problem is to cool the crystal to $123 \mathrm{~K}$ where the linear thermal expansion coefficient of silicon goes to zero [1]. This allows the monochromator to operate without degradation of throughput or brightness. This is usually achieved by pumping liquid nitrogen through the monochromator crystal as has been done at numerous facilities $[2,3]$. This is appropriate for the high power wiggler and undulator sources where hundreds of watts of power are required to be removed through the monochromator crystal. However this cooling scheme is expensive and we sought a less costly scheme for the lower power requirements of a small molecule x-ray diffraction station using bending magnet beamline 11.3.1 at the Advanced Light Source (ALS). This beamline consists of a Be window, channel cut $\mathrm{Si}(111)$ monochromator and a toroidal mirror [4]. The beamline collects 3 mrad of radiation that requires the monochromator crystal to be able to handle 23.4 watts of power at 400 $\mathrm{mA}$ ring current. This power loading can be handled with a Joule Thompson refrigerator (CryoTiger [5]) with no moving or vibrating parts in the cold head. These units are able to cryo-cool up to 25 watts and maintain temperatures in the $70-140 \mathrm{~K}$ range. For larger power loads they can be operated in parallel as has been done with large mosaic cooled X-ray cameras [6]. This paper describes our experimental efforts to develop a simple cryo-cooled channel cut monochromator that is capable of handling the 20 watt power load from a bend magnet beamline. This technology may be relevant for the current trend towards using undulator insertion devices for the generation of micron sized x-ray spots with Kirk Patrick Baez (KB) mirror or zone plate de-magnifier schemes. For these cases, acceptance of the KB mirrors or zone plates is very small (typically $0.5 \times 0.5 \mathrm{~mm}$ ) such that, although the total power output of the insertion device is several hundred watts, the amount of power entering an apertured monochromator could well be in the 10's of watts range and therefore could be simply handled with one of these Joule Thompson refrigerators. The techniques described herein could be potentially applicable in these contexts.

\section{MONOCHROMATOR DESIGN EVOLUTION}

The thermal expansion of silicon versus temperature [1] indicates that to maintain a coefficient of thermal expansion $<1 \times 10^{-7}$ the silicon needs to be maintained in the $117-129 \mathrm{~K}$ range. Figure 1 shows the arrangement of the final cryo-head with the various mechanical/thermal joints that cool the channel cut monochromator. There are 4 joints in total and they will discussed in detail later in section 3 . Figure 2 shows the assembly of the monochromator with a Huber 420 goniometer mounted on a $336 \mathrm{~mm}$ conflat flange. The goniometer rotates the whole cryo-head assembly with channel cut crystal to change wavelength. A rotary vacuum seal is achieved in the standard way with a double Teflon sliding rotary seal 


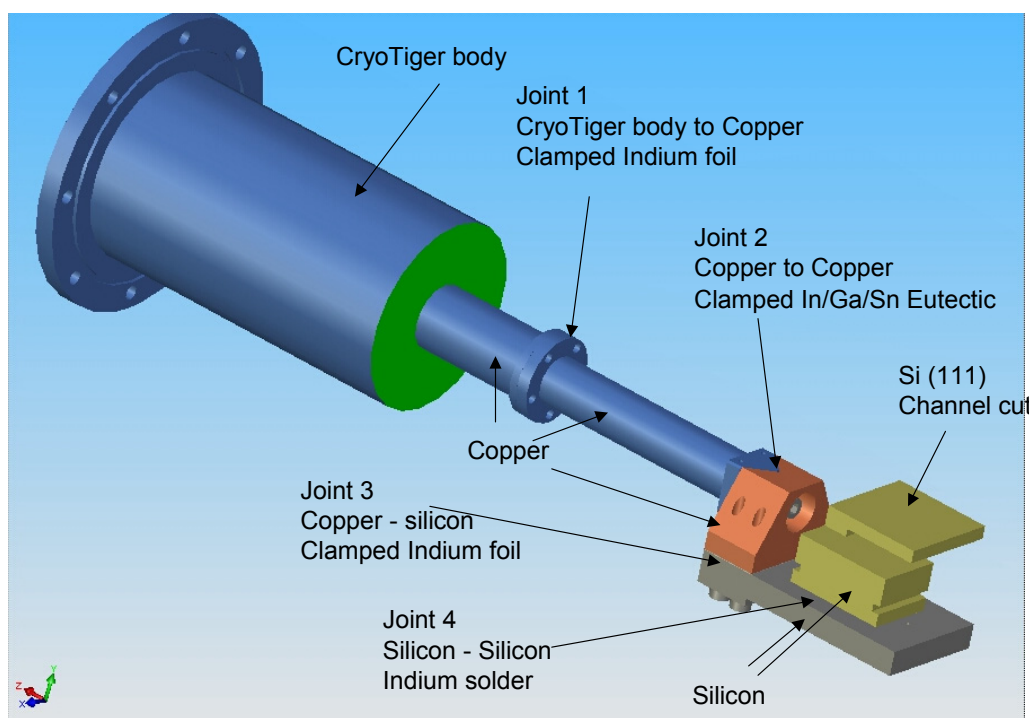

Figure 1. Schematic 3D model of the CryoTiger head and associated connecting brackets to the silicon channel cut monochromator.

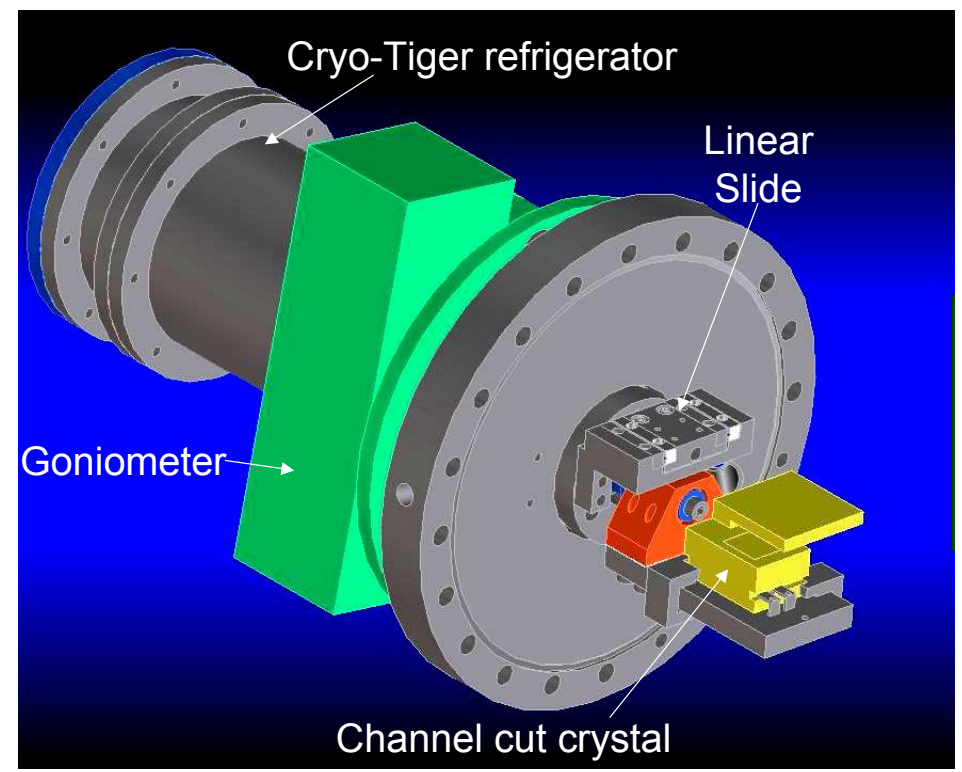

Figure 2. Schematic 3D model of the completed monochromator assembly

with the inter-space between the 2 seals evacuated. The linear slide shown in Figure 2 is attached to the crystal end of the cryo-head assembly ia insulating ceramics? and stabilizes the monochromator as it is mounted off the cryo-head flange some $33 \mathrm{~cm}$ distant. The cryo-head undergoes $\sim 1 \mathrm{~mm}$ thermal contraction from room temperature to its operating temperature of $\sim 120 \mathrm{~K}$ and the linear slide accommodates this motion.

The original design of the cryo-head shown in Figure 1 had only 3 joints, with joint \#3 absent as all the connecting parts from the cryo-head to the crystal where made of copper. Joint $\# 1$ is a clamped indium foil $(0.125 \mathrm{~mm})$. Joint $\# 2$ is clamped with the commonly used indium/gallium/tin eutectic thermal interface (melting point $11^{\circ} \mathrm{C}$ ). The choice of different interface gaskets for these two joints was for historic reasons, but with significant bolting to hold the joints together both joints have performed flawlessly for 23 years of operation consistent with previous observation of bolted joints [7]. As noted earlier the bracket supporting the channel cut silicon crystal was originally made of nickel-plated copper with an indium/gallium/tin eutectic as the thermal interface between the crystal and the copper bracket. The nickelplating of the copper eliminates the etching of the copper by the eutectic. The design of the channel cut 

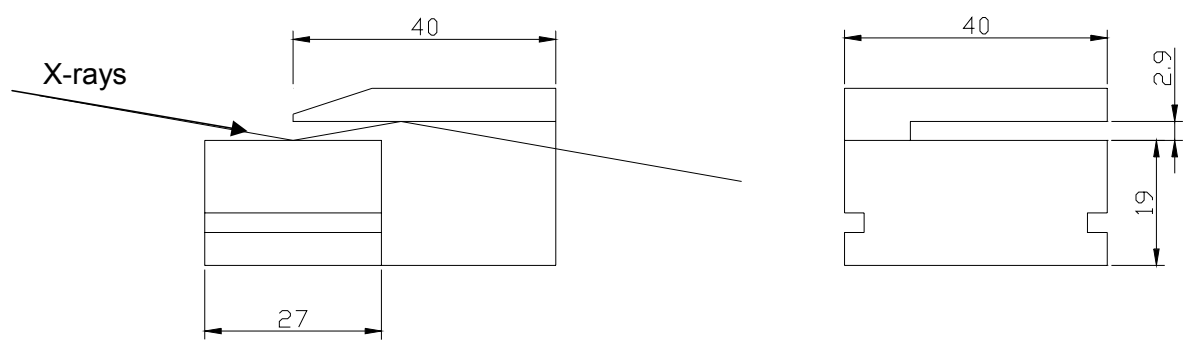

Figure 3. Scaled dimensions of the channel cut monochromator. The top and bottom diffracting surfaces are slightly angled by 0.28 degrees to reduce exit beam motion [4]

crystal (Figure 3) is such that it requires light clamping to hold the lower part of the crystal against the cooled copper bracket. Light clamping prevents distortion of the crystal and is achieved by means of copper beryllium spring clips. The nickel-plated copper and silicon surfaces were wetted by applying the eutectic and scraping with a soft wire brush, then they were lightly clamped together at room temperature. It was noted that the base of the crystal was not flat but was bowed convex by $\sim 5 \mathrm{~m}$. We initially did not change this, arguing that the thicker interface region would help spread out and reduce the strain in the crystal that will inevitably be present due to the different thermal expansion coefficients of the various materials involved.. On cool-down, the eutectic interface performed satisfactorily for a few months of operation but then began to deteriorate as thermocouples attached to the crystal indicated that with beam irradiation the crystal was failing to cool down satisfactorily. The joint took about a year of operation to fail totally - at the end the joint had very high thermal resistance such that the crystal operated at $>20^{\circ} \mathrm{C}$ with beam on. Temperature cycling the cryo-head to re-melt the eutectic had little effect on the performance. During the slow failure of the eutectic joint, an off line program was launched to determine a reliable thermal junction. A photograph of the current final monochromator assembly that shows the spring clips and various thermal joints is shown in Figure 4.

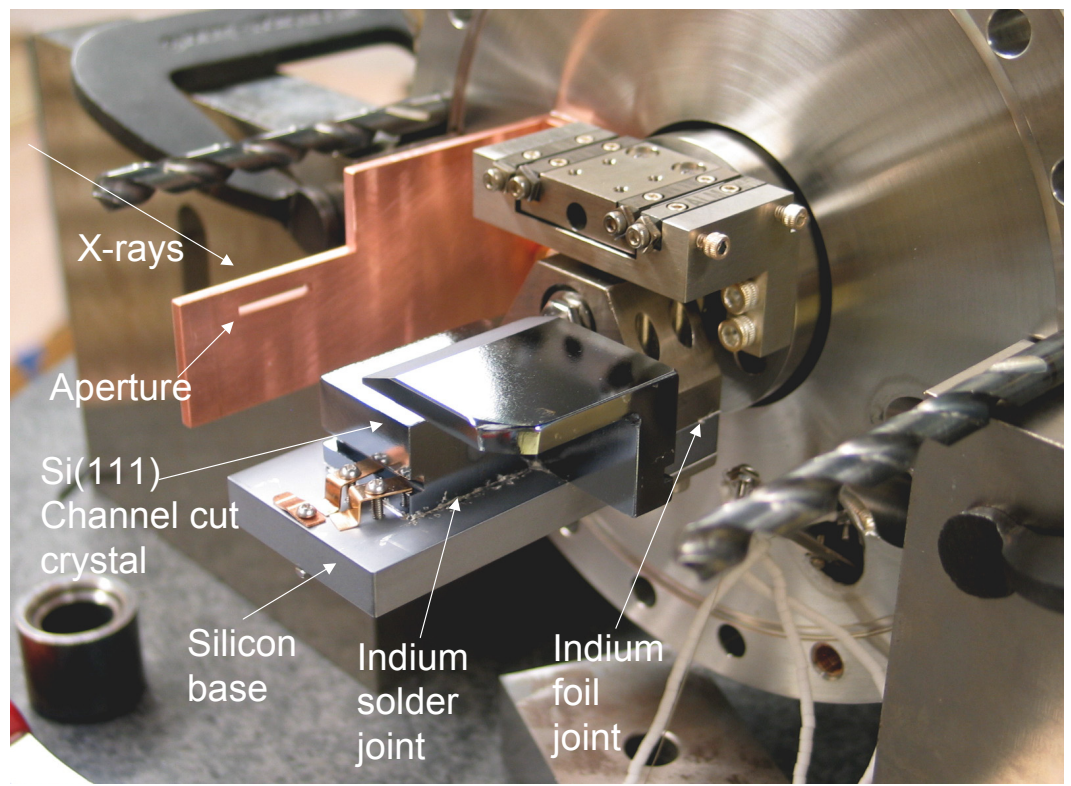

Figure 4. Photograph of the current channel cut monochromator showing hold down clips, aperture thermal joints.

\section{TESTING OF THE CRYO-JOINTS}

The test setup was an evacuated assembly identical to the monochromator in the beamline with the exception that the channel cut monochromator was replaced by a simple block of silicon with a resistor strapped to it through which current could be passed to simulate a 15 watt power load. Thermocouples were placed at strategic points and monitored. Typical cool down plots are shown in Figure 5. Figure 5a shows 
the case for a silicon-to-silicon surface bonded with $\mathrm{In} / \mathrm{Ga} / \mathrm{Sn}$ eutectic. Two thermocouple traces are shown and represent the temperature on either side of the thermal interface under test. The cryo-cooler is switched on at time zero and with no thermal load the two thermocouples register similar temperatures until about $140^{\circ} \mathrm{C}$ where the thermocouples diverge slightly. When power is applied via the resistor, the two thermocouple traces diverge significantly, the upper one representing the monochromator crystal with the thermal load, the lower representing the base on which the channel cut sits. Two cycles of power applied through the resistor are shown. This joint is viewed as a failure (conductance $<0.01 \mathrm{watt} / \mathrm{cm}^{2} /{ }^{\circ} \mathrm{C}$ ) and it is presumed that its failure occurred during cool-down as indicated by the thermocouple divergence at $140^{\circ} \mathrm{C}$. This plot differs markedly from a successful thermal joint shown in Figure $5 \mathrm{~b}$ for a silicon-tosilicon joint bonded with indium solder. Here the 2 thermocouple traces map closely over each other to with in degree indicating very low thermal resistance of the solder joint (conductance $>1.2 \mathrm{watt} / \mathrm{cm}^{2} /{ }^{\circ} \mathrm{C}$ ). Table 1 lists the range of thermal interfaces tried.
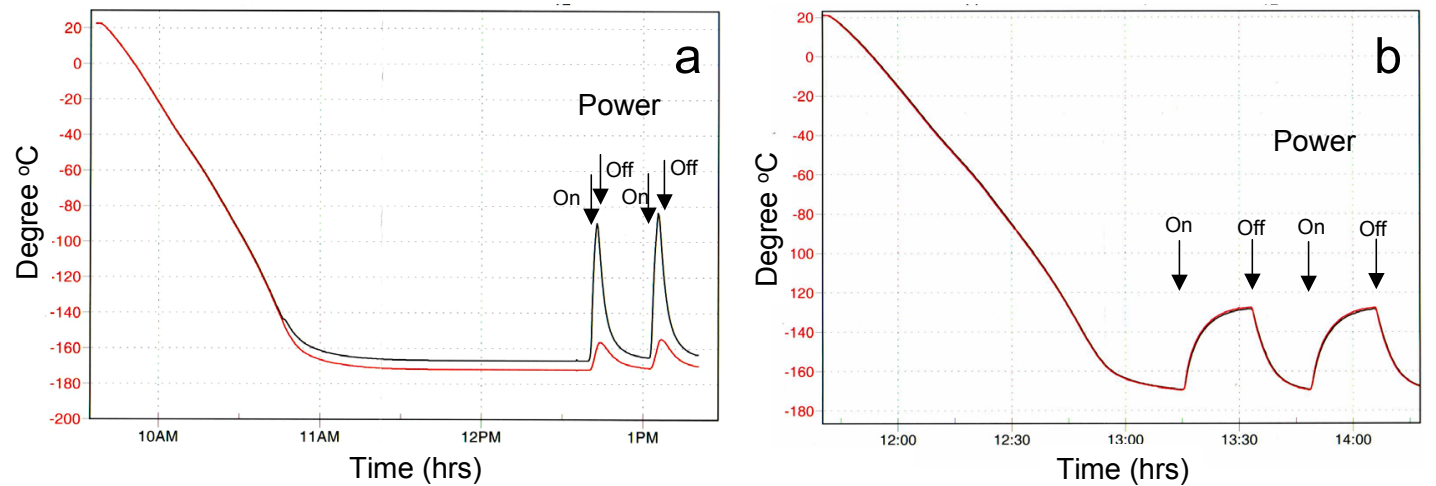

Figure 5. Cool-down traces of 2 thermocouples on either side of a silicon-silicon joint with different thermal joints a) $\mathrm{In} / \mathrm{Ga} / \mathrm{Sn}$ eutectic and $\mathrm{b}$ ) Indium solder. In the case of b) both traces lie on top of each other indicating low thermal resistance of the joint. Twp power cycles of 15 watts are applied to the system.

\begin{tabular}{|c|c|c|c|c|}
\hline & Side 1 & Side 2 & Thermal Joint & $\begin{array}{l}\text { Performance \& } \\
\text { comments }\end{array}$ \\
\hline 1 & $\begin{array}{l}\text { Etched silicon, radius } \sim \\
5 \mathrm{~m} \text { concave }\end{array}$ & Nickel plated copper & $\begin{array}{l}\mathrm{Ga} / \mathrm{In} / \mathrm{Sn} \text { eutectic, } \\
\text { Liquidus }=11^{\circ} \mathrm{C}\end{array}$ & Failed after 2 months \\
\hline 2 & Silicon, lapped & Nickel plated copper & $\mathrm{Ga} / \mathrm{In} / \mathrm{Sn}$ eutectic & $\begin{array}{lccc}\begin{array}{l}\text { Partial } \\
\text { thermal }\end{array} & \text { cyccess } & \text { for } & 2-3 \\
\text { failing } & & \text { before } \\
\text { failing } & & \\
\end{array}$ \\
\hline 3 & Silicon, lapped & Nickel plated copper & $\begin{array}{l}\text { Indium foil - light } \\
\text { pressure }\end{array}$ & $\begin{array}{l}\text { Survived thermal cycles } \\
\text { but had poor thermal } \\
\text { conductance } \\
0.034 \mathrm{watt} / \mathrm{cm}^{2} /{ }^{\circ} \mathrm{C}\end{array}$ \\
\hline 4 & Silicon, lapped & Silicon, lapped & $\mathrm{Ga} / \mathrm{In} / \mathrm{Sn}$ eutectic & Failed on cool-down \\
\hline 5 & Silicon, lapped & Silicon, lapped & Apezion $\mathrm{N}$ grease & $\begin{array}{l}\text { Survived for multiple } \\
\text { thermal cycles but showed } \\
\text { some thermal resistance } \\
0.27 \mathrm{watt} / \mathrm{cm}^{2} /{ }^{\circ} \mathrm{C}\end{array}$ \\
\hline 6 & Silicon, lapped & Silicon, lapped & $\begin{array}{l}\mathrm{In} / \mathrm{Bi} / \mathrm{Sn} \text { solder, } \\
\text { Liquidus }=79^{\circ} \mathrm{C} \text {, type } \\
\# 174 \text { Indium Corp., }\end{array}$ & Failed on cool-down \\
\hline 7 & Silicon, lapped & Silicon, lapped & $\begin{array}{l}\text { Indium soldered } \\
\text { Liquidus }=157^{\circ} \mathrm{C}\end{array}$ & $\begin{array}{l}\text { Survived multiple thermal } \\
\text { cycles. }\end{array}$ \\
\hline
\end{tabular}

Table 1. Range of thermal interfaces tried with their performance. The lapped silicon has a estimated micro-roughness value of $0.2 \mu \mathrm{m} \mathrm{rms}$

The choice of the interfaces for the channel cut crystal evolved from silicon-copper to silicon-silicon as the various failures suggested a better thermal expansion coefficient match the substrates would be in order. Thus joint \#3 (Figure 2) became a requirement. This copper-silicon joint consisted of a thermal interface of 
$0.125 \mathrm{~mm}$ thick indium foil in a simple bolt-clamped assembly. Belleville washers were used to maintain a constant pressure on the joint. The stress in the silicon due to bolt torque $(\sim 100 \mathrm{in} / \mathrm{lbs})$ is considered to be well beyond what could be tolerated in a monochromator crystal unless such a joint was well removed from the diffracting surfaces. Given that we already had the channel cut crystal we did not pursue the creation of the required radically different channel cut monochromator monolithic shape that could use bolt clamping for the thermal interface, but this demonstrates that it could be a possibility. Great care has been taken to ensure that the clamping screws do not crack this piece of silicon. This involved spreading the bolt load over large washers, etching the silicon and rounding off edges. Referring back to Table 1, line \#3 is an attempt to try the above indium foil interface but with light pressure. Various standard vacuum cleaning practices were tied in order to attempt the old weld of the indium sheet to the silicon but with no success. Apezion type $\mathrm{N}$ grease was tried (\#5) as it is commonly used in cryogenic systems - it appeared to survive several thermal cycles but exhibited higher thermal resistance than preferred and was viewed with suspicion by the vacuum aficionados. Low temperature solders were chosen such that the melting temperature to operating temperature range was as small as possible in an attempt to reduce the strain in the joint and hence the transferred strain to the crystal. French's metal (liquidus $47^{\circ} \mathrm{C}$ ) has been used to bond silicon before [8] but we chose not to try this, as the high vapor pressure of the cadmium in the solder content is worrisome when used in vacuum. Further tests were carried out whereby the joint material was simply immersed in liquid nitrogen and its pliability observed when cold. All the joint materials were brittle except for the indium and Apezion $\mathrm{N}$ grease. From this we surmise that all joints fractured due to the differential thermal expansion coefficient between the substrates and the brittle joint material. Sometimes the failure of the brittle joint could be observed acoustically during cool down. The indium solder joint survived due to the ductile nature of the indium.

Finally we summarize the procedure to form the indium solder joint - the two silicon faces were lapped flat and then heated up with $0.125 \mathrm{~mm}$ thick In foil melted on their surfaces. Using a wire brush the indium was wetted to the silicon surfaces. The parts were allowed to cool, then assembled on top of each other and heated up until the indium melted and the solder joint formed. Gravity pressure was used to regulate the indium thickness.

\section{PERFORMANCE}

Figure 6 shows the measured temperature of the beamline 11.3.1 silicon (111) monochromator crystal during a $400 \mathrm{~mA}$ storage ring refill of the ALS. The monochromator is positioned $6 \mathrm{~m}$ from the source, behind a $0.125 \mathrm{~mm}$ thick Beryllium window. A base lower temperature of $-170^{\circ} \mathrm{C}$ is achieved which stabilizes to $-150^{\circ} \mathrm{C}$ in $\sim 15$ mins after a step function increase of 23.4 watts @ 400mA following the shutters opening. Both thermocouples on the channel cut crystal and the supporting backing plate track at the same temperature indicating a low thermal resistance of the joint. The operating temperature of $-150^{\circ} \mathrm{C}$ is the $123 \mathrm{~K}$ temperature required for the zero thermal expansion coefficient point of silicon.

The throughput of the beamline is reasonably close $(\sim \times 2)$ from what might be expected theoretically, so one presumes the crystal strain is reasonably low and does not unduly detract from the performance of the monochromator. However the measurement of the strain in the crystal and the effect on the brightness degradation of the source has not been quantitatively measured. The usual way of making such a crystal strain determination is to measure the double crystal-rocking curve, which one is unable to do with a channel cut monochromator as in this case. Carrying out strain measurements is not straightforward and other ways will need to be explored. Such ideas as determining the increase in source size or measuring the variation in higher order harmonic content and comparing it to theory are possible ways to determine the strain. These have yet to be explored. 


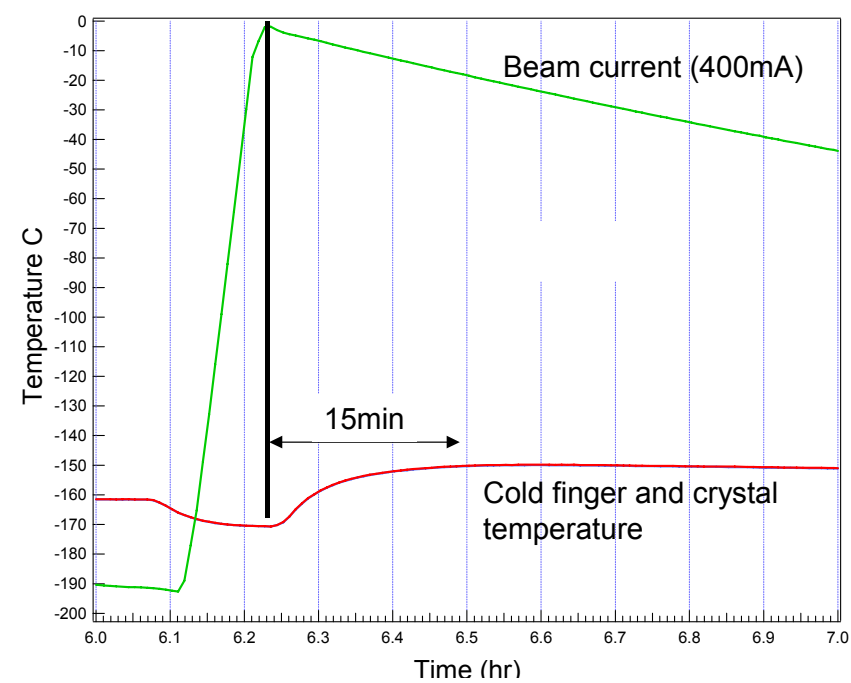

Figure 6. Temperature of the silicon monochromator crystal versus time during a storage ring refill. The ring current goes from $180 \mathrm{~mA}$ to $400 \mathrm{~mA}$ before and after a refill respectively. The shutters are closed during refilling .

\section{CONCLUSIONS}

Indium solder has been used as a thermal joint between a silicon (111) channel cut monochromator and another piece of silicon which is bolted to a Joule Thompson refrigerator such that with a power loading of 23 watts the temperature of the crystal is maintained at $\sim-150^{\circ} \mathrm{C}$, which is close to the ideal temperature of $-146^{\circ} \mathrm{C}$ where the thermal expansion coefficient of silicon goes to zero. The strain imposed on the channel cut by this joint has not been quantified but appears to not qualitatively impact the performance of the channel cut monochromator. The ability of the indium joint to remain viable at low temperatures and the low strain imposed on the crystal is attributed to the ductility of indium, which is maintained at low temperature.

\section{ACKNOWLEDGEMENTS}

We thank useful discussions with A.M.Khounsary who provided encouragement to publish the list of failure results of this work. This work was supported by the Director, Office of Energy Research, Office of Science of the U.S. Department of Energy, under Contract No. DE-AC03-76SF00098.

\section{REFERENCES}

1. K. G. Lyon, G. L. Salinger, C. A. Swenson G. K. White, "Linear thermal expansion measurements on silicon from 6 to $340 \mathrm{~K}$ ", J. Appl. Phys. 48, 865-868, 1977.

2. D.H.Bilderback, "The historical development of cryogenically cooled monochromators for third generation synchrotron soiurces", J.Sync.Rad. 7, 53-60, 2000.

3. M.Rowan, J.W.Peck, T.Rabedeau, "Liquid nitrogen cooled x-ray monochromator for high total power loads", NIM A, vols. 467-468, 400-403, 2001

4. A.C.Thompson, H.A.Padmore, A.G.Oliver, S.J.Teat, R.S.Celestre, S.M.Clark, E.Domning, K.D.Franck, G.Y. Morrison, "A simple high performance beamline for small molecule chemical crystallography", Eighth International Conference on Synchrotron Radiation, ed T.Warwick, AIP, 705, 482-485, 2004

5. Polycold Systems, 3800 Lakeville Hwy, Petaluma, CA 94954, USA

http://www.brooks.com/pages/2159_cryotiger.cfm

6. Mar USA, 1880 Oak Avenue, Evanston, IL 60201 USA, http://www.mar-usa.com

7. A.M.Khounsary, D.Chojnowski, L.Assoufid. "Thermal contact resistance across a copper-silicon interface", SPIE, 3151, 45-51, 1997

8, A.K.Freund, J.R.Artrhur, L.Zhang. "Heat load studies of a water-cooled mini-channel cut monochromaotor for synchrotron x-ray beams", SPIE, 3151, 216-226, 1997 